\title{
Enantioselective Hydrogenation of (E)-and (Z)-Isomeric Ethyl 3-Acetamidobutenoates with Rh-Bisphosphine Complexes: Effects of Substrate Geometry and Solvents on Reaction Rates and Catalyst Reusability
}

\author{
Yong Jian Zhang, ${ }^{\dagger}$ and Eun Joo Rho, and Sang-gi Lee* \\ Life Sciences Division, Korea Institute of Science and Technology, Seoul 130-650, Korea. *E-mail: sanggi@kist.re.kr \\ ${ }^{\dagger}$ School of Chemistry and Chemical Technology, Shanghai Jiao Tong University, Shanghai 200240, P. R. China \\ Received June 7, 2005
}

Key Words : Asymmetric, Hydrogenation, $\beta$-Amino acid, Ionic liquid

Enantiopure $\beta$-amino acids are crucial structural features of numerous biologically active natural products as well as important building blocks for the synthesis of $\beta$-peptides and $\beta$-lactam antibiotics. ${ }^{1}$ Numbers of stoichiometric chiral auxilaries and catalytic methods have been developed to make chiral $\beta$-amino acids. $^{2}$ One of the most promising processes for the convenient preparation of chiral $\beta$-amino acids on large scale is the asymmetric hydrogenation of suitable unsaturated precursors such as $\beta$-acetamido acrylates with $\mathrm{Rh}(\mathrm{I})$ catalysts bearing chiral phosphine ligands. The requisite prochiral substrates are easily available by treatment of $\beta$-keto carboxylates with $\mathrm{NH}_{4} \mathrm{OAc}$ and subsequent acylation. However, while literally thousands of reports are concerned with the Rh-catalyzed enantioselective hydrogenation of related prochiral $\alpha$-acetamido acrylates, only a few devoted to the hydrogenation of $\beta$-analogues as substrates exist. ${ }^{3}$ The main reason for this is probably different behavior in the asymmetric hydrogenation, which had for a long time been attributed to particular substrates such as the isomeric ethyl 3-acetoamido butenoates $(E)-1$ and (Z)-1.<smiles>CCOC(=O)/C=C(\C)NC(C)=O</smiles>

$(E)-1$<smiles>CCOC(=O)/C=C(/C)NC(C)=O</smiles>

$(Z)-1$
Both isomers are produced simultaneously in most synthetic procedures and their individual hydrogenation demands prior separation. Moreover, most reports suggest that the hydrogenation of $Z$-isomers requires much higher hydrogen pressures and longer reaction times than the reduction of their $\mathrm{E}$ analogues and gives inferior enantioselectivity. Recently, we showed for the first time that RhMe-BDPMI (2) ${ }^{4}$ complex can be an effective catalyst for the hydrogenations of $(E)$ - and $(Z)-\beta$-(acylamino)acrylates, in which the $(Z)$-isomers provided the same or even the higher ee values than the corresponding $E$-isomers. ${ }^{5}$ The conversion yields of $(E)$ - and $(Z)$-isomers were largely dependent on the solvent. The $(E)$-isomers were hydrogenated in $\mathrm{CH}_{2} \mathrm{Cl}_{2}$ solvent more effectively, whereas the $(Z)$-isomers in polar $\mathrm{MeOH}$ solvent. In order to understand this important catalytic transformation in more detail, we investigated the effects of solvent on reaction rate using Rh-complex of MeBDPMI 2. We also studied the reusability of the catalysts in an ionic liquid, [bmim] $\left[\mathrm{SbF}_{6}\right]$, for asymmetric hydrogenation of isomeric ethyl 3-acetoamido butenoates $(E)-\mathbf{1}$ and (Z)-1 using Rh-complexes of Me-BDPMI 2 and ionic liquid-grafted BDPMI, ILG-BDPMI 3, which has been designed and used for the asymmetric hydrogenation of simple $N$-acetyl- $\beta$-arylenamides in ionic liquids. ${ }^{6}$ Room temperature molten salts (ionic liquids), especially $1-n$ butyl-3-methylimidazolium (bmim) salts, emerged recently as a potential solvent for catalyst immobilization in catalytic processes. The decisive advantages of ionic liquids over other immobilization systems such as aqueous or fluorous phases with respect to activity, selectivity and re-usability are well documented. ${ }^{7}$

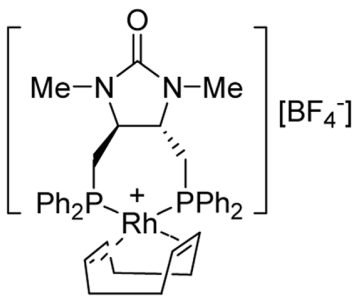

(S,S)-Me-BDPMI (2)

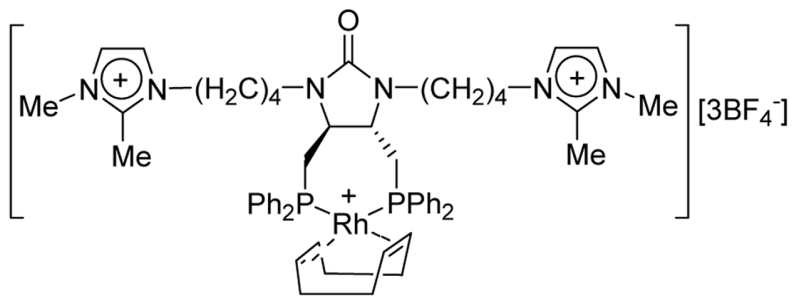

(S,S)-ILG-BDPMI (3)

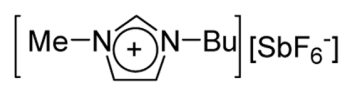

1-Buthyl-3-methylimidazolium hexafluoro antimoate [bmim] $\left[\mathrm{SbF}_{6}\right]$ 
Recently, Heller and Bruneau studied the effects of $\mathrm{H}_{2}$ pressure and reaction temperature on the catalytic activity in asymmetric reduction of $\mathrm{E}$ and $\mathrm{Z}$ isomeric methyl 3acetamidobutenoates with $\mathrm{Rh}(\mathrm{I})$-bisphsophine complexes, and found that the highest enantioselectivities can be achieved for the hydrogenation of both isomeric substrates at room temperature and below, whereas the fastest conversion takes place at $30-50{ }^{\circ} \mathrm{C} .{ }^{8}$ However, as we showed recently, the reactivity of the isomeric substrates are largely dependent on the solvent. ${ }^{5}$ To investigate the effects of solvent on reaction rate in the hydrogenation of isomeric ethyl 3-acetoamido butenoates $(E)-\mathbf{1}$ and (Z)-1, both isomeric substrates was hydrogenated separately in various solvent (1 M solution) using $1 \mathrm{~mol} \%$ of Rh-Me-BDPMI 2 under $1 \mathrm{~atm}$ of $\mathrm{H}_{2}$ pressure at $25^{\circ} \mathrm{C}$ for $30 \mathrm{~min}$, and the reaction was monitored by ${ }^{1} \mathrm{H}$ NMR. As shown in Figure 1, the reaction rate of the isomeric substrates was largely dependent on the solvent. In non-polar solvent, $\mathrm{CH}_{2} \mathrm{Cl}_{2}$, both $E-1$ and Z-1 hydrogenated slowly, and the $E-1$ was hydrogenated faster than the Z-1 as generally known (Figure 1a). When the reaction time was prolonged to $12 \mathrm{~h}$, the $E-\mathbf{1}$ was completely converted to the product, ethyl $(3 R)-3$ acetamido butanoate, with $95 \%$ ee. Although, the enantioselectivity and configuration are the same with those from $E-\mathbf{1}$, the reaction with $Z-1$ was not completed (only $66 \%$ conversion). However, in polar protic solvents such as $\mathrm{MeOH}$ and ${ }^{i} \mathrm{PrOH}$, the $\mathrm{Z}-\mathbf{1}$ was hydrogenated faster than the $E$-1. Especially, in $\mathrm{MeOH}$ solvent, the $E-\mathbf{1}$ and $Z-\mathbf{1}$ isomers were hydrogenated with quite different reaction rate, and thus, over $90 \%$ of the starting Z-1 was converted to the hydrogenated product within $5 \mathrm{~min}$ and completely converted within 20 min with $95 \%$ ee. In contrast, only $23 \%$ of E-1 was hydrogenated in $30 \mathrm{~min}$ (Figure 1b), but the reaction was completed with $92 \%$ ee when the reaction was carried out for $12 \mathrm{~h}$. Very promising results were observed when the reactions were carried out in ${ }^{i} \mathrm{PrOH}$ solvent, which frequently employed as co-solvent for the reactions conducted in imidazolium cation-based ionic liquids. In ${ }^{i} \mathrm{PrOH}$, both isomeric $E-\mathbf{1}$ and $Z-1$ were hydrogenated faster than to the reactions carried out in other solvents. In
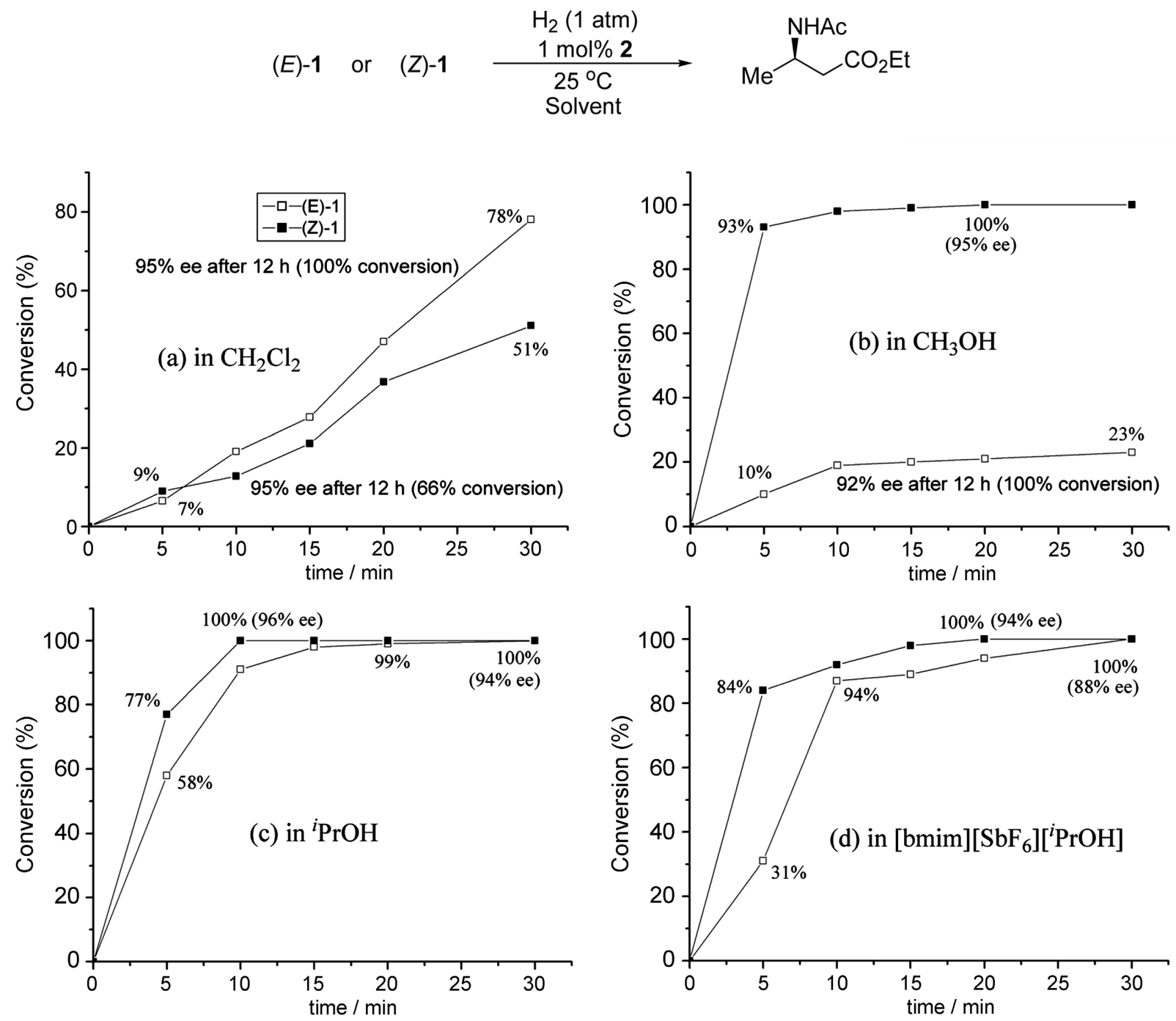

Figure 1. Hydrogenation of (E)-1 and (Z)-1 (0.5 mmol) was carried out in (a) $\mathrm{CH}_{2} \mathrm{Cl}_{2}$, (b) $\mathrm{CH}_{3} \mathrm{OH}$, (c) ${ }^{i} \mathrm{PrOH},(\mathrm{d})[\mathrm{bmim}][\mathrm{SbF}]_{6} / \mathrm{PrOH}_{(1 / 2}$, $\mathrm{v} / \mathrm{v}$ ) using $1 \mathrm{~mol} \%$ of Rh-Me-BDPMI complex under $1 \mathrm{~atm}$ of $\mathrm{H}_{2}$ pressure at $25{ }^{\circ} \mathrm{C}$. The conversion was determined by ${ }^{1} \mathrm{H}$ NMR analysis. 
particular, the Z-1 was hydrogenated completely within 10 min with $96 \%$ ee. ${ }^{9}$ The less reactive $E-1$ (generally known as more reactive in non-polar solvents) was also hydrogenated with increased reaction rate compared to the reactions in other solvents, thus, the reaction was completed within 30 min with $94 \%$ ee. We also investigated the effects of the ionic liquid, $[\mathrm{bmim}]\left[\mathrm{SbF}_{6}\right]$, on the reaction rate. ${ }^{10}$ As shown in Figure $1 \mathrm{~d}$, when the reactions were carried out in $[\mathrm{bmim}]\left[\mathrm{SbF}_{6}\right] /{ }^{i} \mathrm{PrOH}(1 / 2, \mathrm{v} / \mathrm{v})$ co-solvent, both $E$-1 and Z-1 showed decreased reaction rates compared with those in ${ }^{i} \mathrm{PrOH}$ solvent only. Nevertheless, the reactions were completed within $30 \mathrm{~min}$ with slightly decreased $\%$ ees ( $88 \%$ ee for $E-1,94 \%$ ee for $Z-1$ ). These results suggest that the asymmetric hydrogenation of isomeric $E-\mathbf{1}$ and $Z-1$ could be carried out in an ionic liquid without any significant deterioration of catalytic efficiencies.

With these results in hand, we next investigated the reusability of the catalyst immobilized in an ionic liquid. For this purpose, the hydrogenation of isomeric $(E)-\mathbf{1}$ and $(Z)-\mathbf{1}$ was conducted at $25{ }^{\circ} \mathrm{C}$ for $1 \mathrm{~h}$ in an ionic liquid $[\mathrm{bmim}]\left[\mathrm{SbF}_{6}\right] /{ }^{i} \mathrm{PrOH}$ co-solvent using $1 \mathrm{~mol} \%$ of $\mathrm{Rh}-$ BDPMI 2 first. After $1 \mathrm{~h}$ reaction, the ${ }^{i} \mathrm{PrOH}$ layer was separated and the ionic liquid layer was extracted 3 times with ${ }^{i} \mathrm{PrOH}$ to remove the hydrogenated product and the unreacted starting material if the reaction did not completed, and the catalyst immobilized in ionic liquid reused for the next run. As shown in Table 1 (entries 1-7), although the enantioselectivities were retained, decreased conversion was observed upon re-use of the catalyst immobilized in ionic liquid layer. Interestingly, the catalyst reusability was largely depends on the geometry of the starting substrate. In the case

Table 1. Rh-Catalyzed Asymmetric Hydrogenation of $(E)-\mathbf{1}$ and $(Z)-\mathbf{1}$ in $[\mathrm{bmim}]\left[\mathrm{SbF}_{6}\right] / \mathrm{PrOH}^{\mathrm{P}} \mathrm{using} \mathbf{2}$ and $\mathbf{3}$ as catalysts ${ }^{a}$

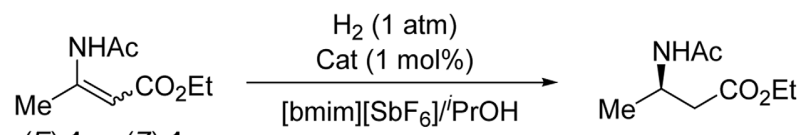

$(E)-1$ or $(Z)-1$

\begin{tabular}{|c|c|c|c|c|c|}
\hline entry & run & substrate & catalyst & Conv. $(\%)^{b}$ & $\% \mathrm{ee}^{c}$ \\
\hline 1 & $1 \mathrm{st}$ & $(E)-\mathbf{1}$ & 2 & 100 & 88 \\
\hline 2 & $2 \mathrm{nd}$ & & & 39 & 87 \\
\hline 3 & $3 \mathrm{rd}$ & & & 18 & 86 \\
\hline 4 & $1 \mathrm{st}$ & $(Z)-\mathbf{1}$ & 2 & 100 & 94 \\
\hline 5 & $2 \mathrm{nf}$ & & & 100 & 93 \\
\hline 6 & $3 \mathrm{rd}$ & & & 61 & 93 \\
\hline 7 & 4th & & & 36 & 91 \\
\hline 8 & $1 \mathrm{st}$ & $(E)-\mathbf{1}$ & 3 & 100 & 95 \\
\hline 9 & $2 \mathrm{nd}$ & & & 87 & 95 \\
\hline 10 & $3 \mathrm{rd}$ & & & 53 & 95 \\
\hline 11 & $1 \mathrm{st}$ & $(Z)-\mathbf{1}$ & 3 & 100 & 90 \\
\hline 12 & $2 \mathrm{nf}$ & & & 100 & 91 \\
\hline 13 & $3 \mathrm{rd}$ & & & 83 & 90 \\
\hline 14 & 4th & & & 71 & 89 \\
\hline
\end{tabular}

${ }^{a}$ The reaction carried out at $25{ }^{\circ} \mathrm{C}$ for $1 \mathrm{~h}$ under 1 atm of $\mathrm{H}_{2}$ pressure using $1 \mathrm{~mol} \%$ of catalyst prepared in situ from 2 (or 3 ) and $\left[\mathrm{Rh}(\mathrm{COD})_{2}\right]\left[\mathrm{BF}_{4}\right]$ in $[\mathrm{bmim}]\left[\mathrm{SbF}_{6}\right] /{ }^{i} \mathrm{PrOH}(1 / 2, \mathrm{v} / \mathrm{v}) .{ }^{b}$ Determined by ${ }^{1} \mathrm{H}$ NMR. ${ }^{c}$ Determined by GC using CP-Chiralsil-Dex-CB column. of $(E)-\mathbf{1}$, the catalytic activity was dramatically decreased in $2^{\text {nd }}$ run (entry 2) whereas it retained in $2^{\text {nd }}$ run for $(Z)-\mathbf{1}$ (entry 5). Similar trend was observed in the hydrogenation with Rh-complex of ionic liquid grafted BDPMI ligand $\mathbf{3}$ (entries 8-14). Although, compared with Rh-BDPMI 2, increased reusability has been observed with Rh-ILGBDPMI 3, the catalytic activity was also decreased upon reuse. Especially, in the hydrogenation of $(E)-\mathbf{1}$, the conversions were more significantly decreased. In ICP-AES analysis of the $i \mathrm{PrOH}$ layer separated from the first runs (entries 8 and 11) with $\mathbf{3}$, no Rh $(<1 \mathrm{ppm})$ and phosphorus $(<3 \mathrm{ppm})$ were detected under detection limit, which may due to the increased the preferential solubility to ILs by attachment of imidazolium ionic tag. Therefore, the catalyst leaching is not the only reason for the decreased catalytic activity of the catalyst $\mathbf{2}$ and $\mathbf{3}$ upon recycling. Although the reason for the substrate dependency of the reusability of the catalyst immobilized in ionic liquid is not clear yet, the active catalytic species or the complexes with the substrates (E)-1 and (Z)-1 may have different stability in ionic liquid.

In summary, kinetic study for the effects of solvents on catalytic activity in Rh-BDPMI complex-catalyzed asymmetric hydrogenation of $(E)$-and $(Z)$-isomeric ethyl 3acetamidobutenoates reveals that both isomers were hydrogenated with high reaction rate in protic ${ }^{i} \mathrm{PrOH}$ whereas much lower reaction rate in non-polar $\mathrm{CH}_{2} \mathrm{Cl}_{2}$ solvent. It has been also found that the reusability of the catalyst immobilized in an ionic liquid is largely depends on the geometry of the prochiral substrates. The superior catalyst reusability has been observed in the hydrogenation of (Z)isomer than in $(E)$-isomer. These results may provide an important insight for the Rh-catalyzed asymmetric hydrogenation of other $\beta$-amidoacetylacrylates.

\section{Experimental Section}

The $\mathrm{Rh}$ complex prepared in situ from the ligand 2 (2.8 $\left.\mathrm{mg}, 3.7 \times 10^{-3} \mathrm{mmol}\right)$ and $\left[\mathrm{Rh}(\mathrm{cod})_{2}\right] \mathrm{BF}_{4}\left(1.3 \mathrm{mg}, 3.1 \times 10^{-3}\right.$ $\mathrm{mmol})$ was dissolved in an ionic liquid, $\left[\mathrm{bmim}^{-}\left[\mathrm{SbF}_{6}\right](1\right.$ $\mathrm{mL})$, and a solution of $\mathbf{1}\left(50 \mathrm{mg}, 3.1 \times 10^{-1} \mathrm{mmol}\right)$ in ${ }^{i} \mathrm{PrOH}$ $(2 \mathrm{~mL})$ were added. The mixture was hydrogenated under 1 atmosphere of $\mathrm{H}_{2}$ pressure at room temperature for $1 \mathrm{~h}$. To determine the conversion and enantioselectivity, the ${ }^{i} \mathrm{PrOH}$ layer was separated, and subjected without any purification into GC equipped with CP-Chirasil-Dex-CB chiral column and ${ }^{1} \mathrm{H}$ NMR. For catalyst recycling, a degassed solution of substrate in ${ }^{i} \mathrm{PrOH}$ was added again to the ionic liquid layer remained in reaction vessel.

Acknowledgements. This work was supported from National Research Laboratory Program form KIST and Center for Molecular Design and Synthesis at KAIST.

\section{References}

1. (a) Enantioselective Synthesis of Amino Acids; Juaristi, E., Ed.; Wiley-VCH: New York, 1997. (b) Cole, D. C. Tetrahedron 1994, 
50, 9517. (c) Gellman, S. H. Acc. Chem. Res. 1998, 31, 173.

2. (a) Tang, T.; Ellman, J. A. J. Org. Chem. 1999, 64, 12. (b) Sibi, M. P.; Shay, H. J.; Liu, M.; Jasperse, C. P. J. Am. Chem. Soc. 1998, 120, 6615. (c) Kobayashi, S.; Ishitani, H.; Ueno, M. J. Am. Chem. Soc. 1998, 120, 431. (d) Chung, X. X. Tetrahedron: Asymmetry 1997, 8, 5. (e) Dumas, F.; Mezrhab, B.; d'Angelo, J. J. Org. Chem. 1996, 61, 2293. (f) Davis, F. A.; Szewczyk, J. M.; Reddy, R. E. J. Org. Chem. 1996, 61, 2222. (g) Enders, D.; Wahl, H.; Bettray, W. Angew. Chem., Int. Ed. Engl. 1995, 34, 455.

3. (a) Achiwa, K.; Soga, T. Tetrahedron Lett. 1978, 13, 1119. (b) Furukawa, M.; Okawara, T.; Noguchi, Y.; Terawaki, Y. Chem. Pharm. Bull. 1979, 27, 2223. (c) Zhu, G.; Chen, Z;; Zhang, X. J. Org. Chem. 1999, 64, 6907. (d) Heller, D.; Holz, J.; Drexler, H.-J.; Lang, J.; Drauz, K.; Krimmer, H.-p.; Börner, A. J. Org. Chem. 2001, 66, 6816. (e) Yasutake, M.; Gridnev, I. D.; Higashi, N.; Imamoto, T. Org. Lett. 2001, 3, 1701. (f) Lubell, W. D.; Kitamura, M.; Noyori, R. Tetrahedron: Asymmetry 1991, 2, 543. (g) Pena, D.; Minnaard, A. J.; de Vries, J. G.; Feringa, B. L. J. Am. Chem. Soc. 2002, 124, 14552. (h) Tang, W.; Zhang, X. Org. Lett. 2002, 4, 4159. (i) Holz, J.; Monsees, A.; Jiao, H.; You, J.;
Komarov, I. V.; Fischer, C.; Drauz, K.; Borner, A. J. Org. Chem. 2003, 68, 1701.

4. Lee, S.-g.; Zhang, Y. J.; Song, C. E.; Lee, J. K.; Choi, J. H. Angew. Chem. Int. Ed. 2002, 41, 847.

5. Zhang, Y. J.; Lee, S.-g. Org. Lett. 2002, 4, 2429

6. Lee, S.-g.; Zhang, Y. J.; Piao, J. Y.; Yoon, H.; Song, C. E.; Choi, J. H.; Hong, J. Chem. Commun. 2003, 2624.

7. (a) Dupont, J.; de Souza, R. F.; Suarez, P. A. Z. Chem. Rev. 2002, 102, 3667. (b) Baudequin, C.; Baudoux, J.; Levillain, J.; Cahard, D.; Gaumont, A.-C.; Plaquevent, J.-C. Tetrahedron: Asymmetry 2003, 14, 3081. (c) Song, C. E. Chem. Comm. 2004, 1033. (d) Lee, S.-g.; Park, J. H. Bull. Korean Chem. Soc. 2002, 23, 1367.

8. (a) Heller, D.; Drexler, H.-J.; You, J.; Baumann, W.; Drauz, K.; Krimmer, H.-P.; Börner, A. Chem. Eur. J. 2002, 8, 5196. (b) Jerphagnon, T.; Renaud, J.-L.; Demonchaux, P.; Ferreira, A.; Bruneau, C. Tetrahedron:Asymmetry 2003, 14, 1973.

9. In previous study in reference 5 , the reaction in ${ }^{i} \mathrm{PrOH}$ did not completed, which has been corrected.

10. $[\mathrm{bmim}]\left[\mathrm{SbF}_{6}\right]$ was selected because of its lower solubility in ${ }^{i} \mathrm{PrOH}$, which was found in our previous study, see reference 6 . 